\title{
Resilience, Hope, and Subjective Happiness Among the Turkish Population: Fear of COVID-19 as a Mediator
}

\author{
Seydi Ahmet Satici ${ }^{1}$ (D) Ahmet Rifat Kayis ${ }^{2}$ (D) Begum Satici $^{1}$ (D) \\ Mark D. Griffiths ${ }^{3}$ (D) Gurhan Can $^{4}$ (D)
}

Accepted: 13 November 2020 /Published online: 3 December 2020

(C) The Author(s) 2020

\begin{abstract}
Psychology deals with not only mental disorders but also psychological strengths within individuals. Psychological strengths will play an important role in struggling with the global novel coronavirus 2019 (COVID-19) pandemic. The present study tested a model concerning the relationship between resilience, hope, and subjective happiness using structural equation modeling to identify the mediating role of fear of COVID-19. A cross-sectional survey was conducted among a convenience sample of 971 Turkish individuals (aged 18 to 74 years) from 75 of 81 cities in Turkey. The survey included the Subjective Happiness Scale, Fear of COVID-19 Scale, Brief Resilience Scale, and the Dispositional Hope Scale, and data were analyzed using structural equation modeling (SEM). The SEM demonstrated an association between resilience-hope and subjective happiness was mediated by fear of COVID-19 $(\mathrm{CMIN} / d f=2.664, \mathrm{CFI}=0.994, \mathrm{NFI}=$ 0.984, TLI $=0.984, \mathrm{GFI}=0.994, \mathrm{RMSEA}=0.044, \mathrm{SRMR}=0.024, \mathrm{AIC}=81.334$, $\mathrm{ECVI}=0.084)$. Resilience had a direct effect and an indirect effect on subjective happiness via fear of COVID-19. Hope also had a direct effect and an indirect effect on subjective happiness via fear of COVID-19. Consequently, in the fight against COVID-19, individuals who are resistant to stress and have a belief that they can find a way to cope can help prevent the fear of COVID-19 and so enhance good mental health.
\end{abstract}

Keywords COVID-19 $\cdot$ Subjective happiness $\cdot$ Resilience $\cdot$ Hope $\cdot$ Fear of COVID-19

\section{Introduction}

The novel coronavirus disease 2019 (COVID-19) pandemic is a serious health threat that (at the time of writing) has infected more than 43 million people worldwide and resulted in the death of

Mark D. Griffiths

mark.griffiths@ntu.ac.uk

Extended author information available on the last page of the article 
more than 1.1 million individuals (World Health Organization 2020). From March 11, when the first case of COVID-19 was reported in Turkey, to October 30, over 370,800 cases had been reported and over 10,000 individuals had died from it (Republic of Turkey Ministry of Health 2020). Turkey's government enforced many measures to mitigate the spread of COVID-19, such as enforcing spatial distancing, the use of medical face masks, closing schools, encouraging self-isolation, and quarantining individuals returning from abroad. With COVID-19 having spread globally, the absence of a scientifically proven cure, and the difficulty in controlling it, the resulting situation has led to devastating economic, social, and psychological effects.

\section{COVID-19 and Psychological Impact}

One of the most important issues regarding COVID-19 is preventing adverse psychological effects among individuals. Research carried out at the start of the pandemic in China showed that symptoms of depression, anxiety, stress, and panic disorders had increased compared to levels prior to the COVID-19 outbreak (Qiu et al. 2020; Wang et al. 2020). COVID-19 can also trigger panic and fear among some individuals (Ahorsu et al. 2020). Such feelings can arise from the fear of being infected, infecting others, dying, and/or losing loved ones. Additionally, concerns such as not being able to receive the necessary medical care or the possibility of losing one's job as a result can also weigh heavily on the mind of the individual (Montemurro 2020; Ornell et al. 2020; Pakpour and Griffiths 2020).

Another possible reason that may cause fear and panic relating to COVID-19 is the measures taken to inhibit the spread of the virus such as spatial distancing, self-quarantine, and restricting time outdoors (Anderson et al. 2020; Wilder-Smith et al. 2020). These measures have forced individuals to stay at home leading to a restriction of their social relationships. Consequently, this has led to individuals being deprived of social support, which is a likely protective factor in terms of fear of COVID-19 as a means of coping (Chou 2000; Kassam 2019). The continual following of news and developments concerning COVID-19 (especially via social media which may include misinformation) is also a factor that risks increasing fear of COVID-19 (Ahorsu et al. 2020). Additionally, although fear has strengths such as sensitizing and persuading dangerous situations, it can also cause maladaptive coping behaviors if the level of fear is too great (Witte and Allen 2000). Therefore, the importance of psychological protective factors cannot be understated in regard to the fear of COVID-19.

\section{Resilience as a Factor in Preventing Poor Mental Health}

One of the demonstrable protective factors in preventing psychological disorders is resilience. Resilience is the speedy recovery and the ability to return to daily functioning, after having experienced stressful life events that have resulted in functional breakdown (Carver 1998). In other words, resilience can be viewed as the ability to stay strong during challenging times (Jackson et al. 2007). During COVID-19 pandemic, the resilience of individuals may have decreased while their vulnerability may have increased (Sadati et al. 2020). This is why resilience can be considered as an important component in coping with the fear, panic, anxiety, and stress resulting from COVID-19. The finding that resilience interventions help in the creation of effective coping strategies for stress supports this view (Steinhardt and Dolbier 2008). Alongside this, resilience has positive associations with variables such as good psychological well-being (Sagone and De Caroli 2014; Souri and Hasanirad 2011), subjective 
well-being (Bajaj and Pande 2016), and subjective happiness (Choi and Kim 2018), all of which are indicators of good mental health. Furthermore, it has also been posited that resilience is not only protective in terms of mental health but also economically and biologically (Djalante et al. 2020). Consequently, strong resilience is likely to be associated with a low fear of COVID-19.

\section{Hope as a Factor in Preventing Poor Mental Health}

Hope is the belief that the paths to reach one's goals can be found and the motivation in trying out those different paths (Snyder et al. 2002). From this perspective, a hopeful individual, even under challenging life conditions, has the strength to find alternative solutions and to apply them. Consequently, hope can be seen as a protective factor in mental well-being in relation to the difficult conditions created by COVID-19. The COVID-19 pandemic has forced individuals to adopt many new modes of behavior in relation to areas such as personal hygiene, working conditions, and social relationships (Ahorsu et al. 2020; Anderson et al. 2020). In light of this, if it is perceived that having to develop new modes of behavior as protection against COVID-19 as a goal, then it is posited that hope will be a strong factor when trying to attain such a goal. One aspect of hope is that it encompasses positive expectations for the future (Snyder 2000), so naturally an individual may have hopeful expectations that COVID-19 will pass. This motivates the individual into making effort regarding both the present and the future. Moreover, there are findings demonstrating that hope has a negative association with psychological disorders (Glass et al. 2009; Rawdin et al. 2013). Similarly, interventions programs that facilitate hope decrease psychological symptoms (Rustøen et al. 2011). On the other hand, hope has a positive association with subjective happiness (Sariçam 2015) and subjective well-being (Kato and Snyder 2005; Satici 2016; Shenaar-Golan 2017; Yalçın and Malkoç 2015). When these findings are taken as a whole, hope can be thought of as playing a protective role that stimulates good mental health and counteracts psychological problems caused by COVID-19.

\section{Happiness and Good Mental Health}

One of the indicators of good mental health is subjective happiness, and the fear of COVID-19 (discussed in the next section) has the potential to affect an individual's subjective happiness. Subjective happiness is the balance of positive and negative feelings and satisfaction in one's life (Diener et al. 2009). In essence, the more that an individual experiences more positive than negative feelings, and the more satisfaction they have in their life, the greater they will feel happiness. However, infectious diseases have a negative effect on happiness (Lau et al. 2008). Therefore, it can be posited that the fear of COVID-19 will decrease happiness among individuals and impact their mental health negatively. Many studies have in fact pointed to the possibility of COVID-19 causing psychological disorders (e.g., Holmes et al. 2020; Mucci et al. 2020). Alongside this, positive psychology-based interventions programs have been found to decrease fear and increase happiness (Lambert et al. 2019). This finding supports the notion that fear of COVID-19 will have a negative correlation with subjective happiness. Also, factors thought to help prevent fear of COVID-19, such as resilience (Choi and Kim 2018; Yildirim and Belen 2019) and hope (Aghababaei et al. 2016; Satici 2016), have a positive correlation with subjective happiness. 


\section{Fear of COVID-19}

Fear is a natural reaction in the face of danger. For this reason, it is inevitable that fear is experienced in relation to COVID-19. In fact, fear can be a source of motivation that leads individuals to take precautions against dangerous situations such as the COVID-19 pandemic (Nabi and Myrick 2019). However, the uncertainty surrounding the dangers of COVID-19 means that fear can become both chronic and disproportionate (Mertens et al. 2020). The Fear of COVID-19 Scale (FCVS-19) developed by Ahorsu et al. (2020) has quickly become a widely used instrument to assess the fear of COVID-19. The FCVS-19 has already been adapted to many different languages including Arabic (Alyami et al. 2020), Bangla (Sakib et al. 2020), English (Harper et al. 2020 [in the UK]; Winter et al. 2020 [in New Zealand]); Hebrew (Bitan et al. 2020), Italian (Soraci et al. 2020), Japanese (Masuyama et al. 2020), Malay (Pang et al. 2020), Portuguese [in Brazil] (Abad et al. 2020), Russian (Reznik et al. 2020), and Turkish (Satici et al. 2020) which has stimulated much of research on fear of COVID-19. These many studies in such a short period of time show that the fear of COVID-19 is being researched worldwide in terms of examining the psychological effects of fear in the COVID-19 pandemic.

\section{The Present Study}

To date, the world has not experienced a widespread virus that has impacted on the world the way that COVID-19 has. The first COVID-19 case in Turkey was reported on March 11, 2020, and since then, many measures have been taken to isolate and try and control the speed at which the virus is spreading. These measures have had a negative impact on economy and social lives as well as creating fear, panic, and anxiety. That is why it is crucial to determine the factors that protect the mental health of individuals and their daily functioning.

Focusing on the strengths of a person instead of psychological disorders is essential in terms of protective and preventive mental health services. It therefore follows that in the battle against the negative outcomes of COVID-19, focusing on the individual's strengths is an important factor in preventing the emergence of psychological disorders. In this context, both hope (Griggs 2017; Trezise et al. 2018) and resilience (Reyes et al. 2019; Shin et al. 2019) as protective factors in helping prevent psychological disorders developing will play important roles in countering the negative effects of COVID-19.

Studies that have evaluated the effects COVID-19 from a mental health perspective, commonly draw attention to psychological disorders that it may lead to (e.g., Conversano et al. 2020; Qiu et al. 2020; Zhang et al. 2020). However, it is argued that focusing on indicators that comprise a healthy psychological outlook such as resilience, hope, well-being, and happiness is more effective in developing good mental health (Peterson 2006; Peterson and Seligman 2004). In this respect, examining the association between fear of COVID-19 and subjective happiness (which is a psychological strength) can provide important information on how individuals can become stronger mentally during the COVID-19 pandemic.

Consequentially, the protective factors associated with overcoming the fear of COVID19 should be examined, not just the psychological disorders that it may lead to. Alongside this, another area necessitating examination concerns what the protective factors and what might happen if an individual's strengths are weakened. In relation to the fear of COVID19, previous research has not examined resilience and hope as protective factors, or subjective happiness as an indicator of good mental health. Therefore, the role of fear of COVID-19 as a mediator between resilience, hope, and subjective happiness was tested 
in the present study. Consequently, two hypotheses (Hs) were formulated based on the aforementioned literature: $\left(\mathrm{H}_{1}\right)$ the relationship between resilience and subjective happiness will be mediated by fear of COVID-19 and $\left(\mathrm{H}_{2}\right)$ the relationship between hope and subjective happiness will be mediated by fear of COVID-19. A graphical model of the hypothesized relationships is shown in Fig. 1:

\section{Method}

\section{Participants and Procedure}

The study sample comprised 971 Turkish volunteers consisting of 711 females $(73.2 \%)$ and 260 males $(26.8 \%)$. Their ages ranged from 18 to 74 years $(M=24.46$ years, $\mathrm{SD}=7.38)$. Data were obtained from a cross-sectional study using convenience sampling in the first week of May 2020. A web-based questionnaire was created and distributed using a link on Turkish social networking sites. After giving brief information about the study, informed consent was obtained from the participants. Participants completed four self-report measures which were anonymous to avoid biased responses. The web-based questionnaire was designed so that participants could withdraw at any time. Additionally, when they wanted to submit the survey, they were asked if they could complete all the items. Therefore, there were no missing data among the surveys that were submitted.

\section{Measures}

Subjective Happiness This was assessed using the Subjective Happiness Scale (SHS; Lyubomirsky and Lepper 1999), a four-item self-report scale with items (e.g., To what extent does this characterization describe you? "Some people are generally very happy. They enjoy life regardless of what is going on, getting the most out of everything") responded to on a scale from 1 (not at all) to 7 (a great deal). The total score ranges between 4 and 28, with lower scores

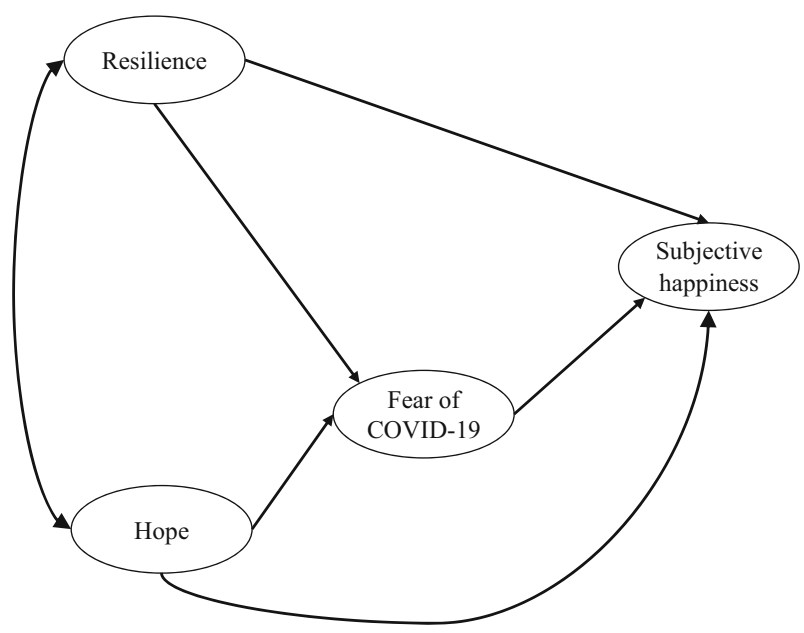

Fig. 1 The model of the proposed relationships between the study variables 
indicating poorer subjective happiness. Adaptation of the SHS into Turkish was carried out by Akin and Satici (2011) and has very good internal consistency reliability $(\alpha=.86)$, as well as good structure validity (Akin and Satici 2011). In the present study, the reliability coefficients were good $(\alpha=.74$ and $\omega=.75)$.

Fear of Coronavirus-19 This was assessed using the Fear of COVID-19 Scale (FCVS-19; Ahorsu et al. 2020), a seven-item self-report scale with items (e.g., "I cannot sleep because I'm worrying about getting coronavirus-19") responded to on a scale from 1 (strongly disagree) to 5 (strongly agree). The total score ranges between 7 and 35, with higher scores indicating greater fear of COVID-19. Adaptation of the FCVS-19 into Turkish was carried out by Satici et al. (2020) and has very good internal consistency reliability $(\alpha=.85)$, as well as good structure validity (Satici et al. 2020). In the present study, the reliability coefficients were very good $(\alpha=.85$ and $\omega=.85)$.

Resilience This was assessed using the Brief Resilience Scale (BRS; Smith et al. 2008), a sixitem self-report scale with items (e.g., "I tend to bounce back quickly after hard times") responded to on a scale from 1 (strongly disagree) to 5 (strongly agree). The total score ranges between 6 and 30, with lower scores indicating poorer resilience. Adaptation of the BRS into Turkish was carried out by Doğan (2015) and has very good internal consistency reliability $(\alpha=.83)$, as well as good structure validity (Doğan 2015). In the present study, the reliability coefficients were very good $(\alpha=.81$ and $\omega=.81)$.

Hope This was assessed using the Dispositional Hope Scale (DHS; Snyder et al. 1991), a 12item self-report scale with items (e.g., "I can think of many ways to get out of a jam") responded to on a scale from 1 (definitely false) to 8 (definitely true). The DHS comprises two subscales: agency and pathway. Adaptation of the BRS into Turkish was carried out by Tarhan and Bacanlı (2015) and has very good internal consistency reliability $(\alpha=.86)$, as well as good structure validity (Tarhan and Bacanl1 2015). In the present study, the reliability coefficients were very good $(\alpha=.87$ and $\omega=.87)$.

\section{Data Analysis}

First, bivariate correlations (Pearson's coefficient) were calculated. Second, descriptive statistics, convergent and discriminant validity, and internal reliabilities were examined. Third, a mediation model analysis based on a two-step approach SEM (measurement and structural model) recommended by Anderson and Gerbing (1988) was performed. Maximum likelihood estimation was used in the SEM. The following model fit indices were examined: root mean square error of approximation (RMSEA), standardized root mean square residual (SRMR), comparative fit index (CFI), normed fit index (NFI), TuckerLewis index (TLI), and goodness of fit (GFI) such that RMSEA and SRMR values $\leq .08$, CFI, NFI, TLI, and GFI values $\geq .90$ generally represent acceptable fit to the observed data (Hu and Bentler 1999; MacCallum et al. 1996). In addition, the parceling technique that is used to reduce measurement errors in single factor measurement (Little et al. 2002) was also included in the SEM. Therefore, the uni-dimensional SHS, FCVS-19, and BRS were divided into two parcels. Data were analyzed utilizing IBM SPSS Statistics 22, AMOS 24, and JASP 0.11.1.0. 


\section{Ethics}

The study procedures were carried out in accordance with the Declaration of Helsinki and were approved by the Artvin Coruh University Scientific Research and Ethical Review Board (REF = E.5374) and Ministry of Health (Document Name: 2020-05-07T22-10-45). All participants provided informed consent and were informed that they could withdraw at any time from the study.

\section{Results}

\section{Relationships Between the Variables}

Table 1 shows that subjective happiness was negatively correlated with fear of COVID-19 ( $r=$ $-.25, p<.001)$. Fear of COVID-19 was negatively correlated with resilience $(r=-.42$, $p<.001)$ and hope $(r=-.24, p<.001)$. Subjective happiness was positively correlated with resilience $(r=.41, p<.001)$ and hope $(r=.34, p<.001)$.

\section{Structural Equation Modeling}

\section{Measurement Model}

The measurement model included four latent variables (subjective happiness, fear of COVID19, resilience, and hope) and eight observed variables. All the fit indices for the measurement model indicated that they were a suitable fit to the data: RMSEA $=0.041, \mathrm{SRMR}=0.021$, $\mathrm{CMIN} / d f=2.667, \mathrm{CFI}=0.993, \mathrm{NFI}=0.988, \mathrm{TLI}=0.985, \mathrm{GFI}=0.991$. To test the measurement model, composite reliability (CR) and discriminant validity were also checked. Table 2 shows the factor loadings, mean, standard deviation, composite reliability (CR), average variance extract (AVE), and reliability coefficient (Cronbach's $\alpha$ and Mc Donald's $\omega$ ) used to check the convergent validity of constructs. The results showed that factor loadings were between 0.72 and 0.94 and all of them were statistically significant. In addition, the results indicated that CRs were higher than 0.7 and the AVEs were greater than 0.5. The model had adequate convergent and discriminant validity according to the criteria proposed by Bagozzi and Yi (1988) and Fornell and Larcker (1981). All the reliability coefficients ( $\alpha \geq .74$ and $\omega \geq .75$ ) were good. Consequently, these results demonstrated that the observed variables were strong representatives of the latent constructs.

Table 1 Correlations and discriminant validity

\begin{tabular}{lrrrr}
\hline Variable & \multicolumn{1}{l}{ 1 } & 2 & 3 & 4 \\
\hline 1. Subjective happiness & .76 & & & \\
2. Fear of COVID-19 & -.25 & .90 & .74 & .42 \\
3. Resilience & .41 & -.24 & .48 & .84 \\
4. Hope & .34 & -.48 & \\
\hline
\end{tabular}

Diagonals (in italic) represent square root of AVE while off diagonals represent correlations 
Table 2 Factor loadings, descriptive statistics, CR, AVE, and reliabilities

\begin{tabular}{lllllllll}
\hline Latent variables & Indicator & Loadings & $M$ & SD & CR & AVE & $\alpha$ & $\omega$ \\
\hline Subjective happiness & SHPar 1 & .80 & 6.42 & 1.69 & .75 & .60 & .738 & .746 \\
& SHPar 2 & .76 & 8.10 & 1.74 & & & & \\
Fear of COVID-19 & FCPar 1 & .94 & 10.36 & 3.23 & .90 & .82 & .845 & .847 \\
& FCPar 2 & .87 & 7.98 & 2.58 & & & & .805 \\
Resilience & RSPar 1 & .72 & 9.85 & 2.38 & .70 & .54 & .807 \\
Hope & RSPar 2 & .76 & 9.76 & 2.61 & & & .865 & .867 \\
& Agency & .79 & 24.73 & 4.14 & .82 & .70 & .865 \\
\hline
\end{tabular}

SHPar parcels of subjective happiness, FCPar parcels of fear of COVID-19, RSPar parcels of resilience, CR composite reliability, $A V E$ average variance extract

\section{Structural Model}

To test the hypotheses, the partial mediation model was tested and compared to the full mediation model. The partial mediation model indicated an acceptable fit to the data $(\mathrm{CMIN} / d f=2.664, \mathrm{CFI}=0.994, \mathrm{NFI}=0.984, \mathrm{TLI}=0.984, \mathrm{GFI}=0.994, \mathrm{RMSEA}=0.044$, $\mathrm{SRMR}=0.024, \mathrm{AIC}=81.334, \mathrm{ECVI}=0.084)$. Compared to the partial mediation model, the fit of the full model yielded worse fit indices $(\mathrm{CMIN} / d f=7.875, \mathrm{CFI}=0.965, \mathrm{NFI}=0.960$, $\mathrm{TLI}=0.939, \mathrm{GFI}=0.969, \mathrm{RMSEA}=0.084, \mathrm{SRMR}=0.083, \mathrm{AIC}=165.999, \mathrm{ECVI}=0.171)$, and its CMIN/ $d f$, RMSEA, and SRMR values were above the reference values that indicate an acceptable fit. The partial mediation model was preferred because the AIC and ECVI coefficients were lower than the full mediation model's AIC and ECVI coefficients. In addition, the chi-square test indicated that the partial mediation model provided a better fit to the data than the full mediation model $\left(\Delta \chi^{2}=88.67, d f=2, p<.001\right)$. In the partial mediation model, Cohen's effect size was calculated for power analysis and a large effect size was determined (Cohen's $\left.f^{2}=.421\right)$.

The partial mediation model showed that higher resilience predicted lower fear of COVID$19(\gamma=-0.60, p<.01)$ and higher subjective happiness $(\gamma=0.28, p<.01)$. In addition, a higher level of hope was associated with a lower fear of COVID-19 $(\gamma=-0.12, p<.05)$ and a higher level of subjective happiness $(\gamma=0.17, p<.01)$. As expected, a higher fear of COVID-19 predicted lower subjective happiness $(\gamma=-0.21, p<.01)$. Finally, the relationship between resilience and subjective happiness was partially mediated by fear of COVID-19. The bias corrected estimation of the standardized indirect effect was $0.126(p<.01 ; \mathrm{BCa} 95 \%$ lower limit $=-.701$ to upper limit $=-.521)$. Also, the relationship between hope and subjective happiness was partially mediated by fear of COVID-19 $(0.024, p<.05$; BCa95\% lower limit = .037 to upper limit $=.219$ ). Taken together, this analysis demonstrated that resilience and hope had a direct positive influence on subjective happiness and indirectly via its negative effect on fear of COVID-19. All standardized factor loadings are presented in Fig. 2. Also, the indirect and total effects for bootstrapping are presented in Table 3.

\section{Discussion}

Resilience and hope are protective factors in preventing mental disorders from developing (Griggs 2017; Reyes et al. 2019) and have a positive association with increased subjective 


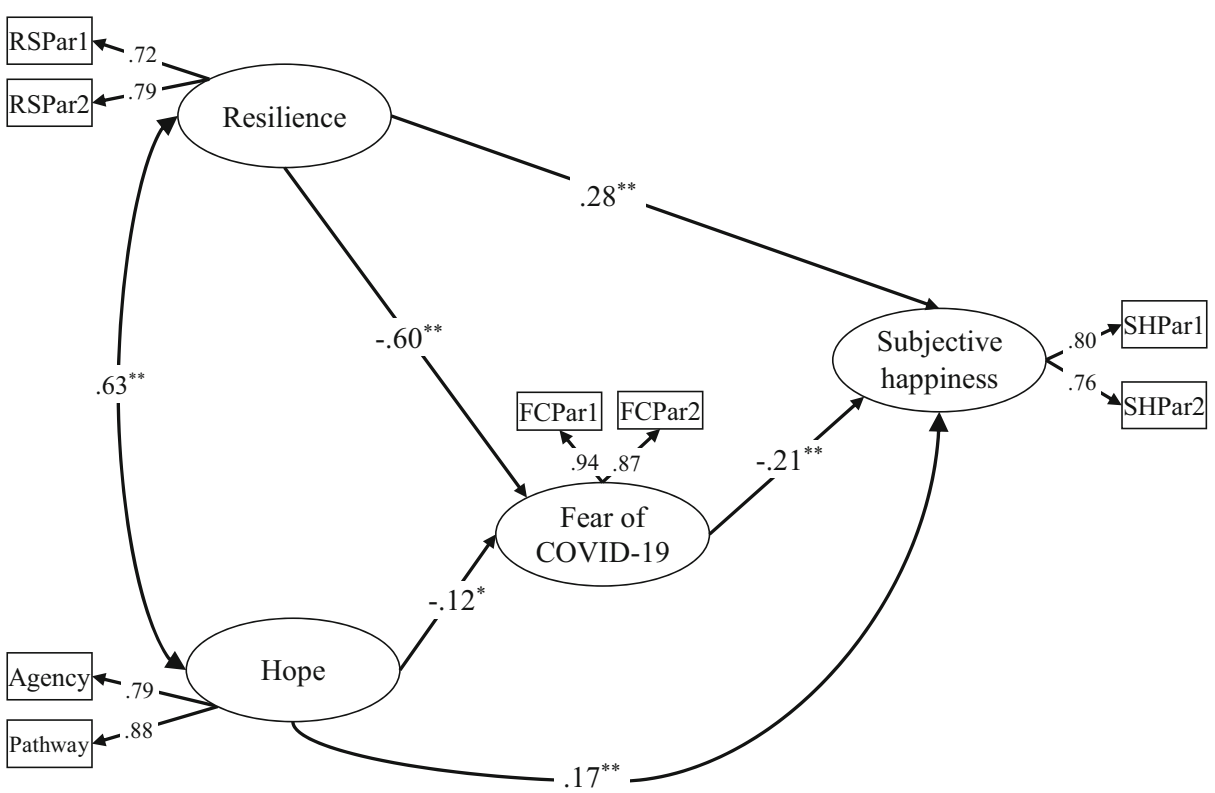

Fig. 2 Standardized factor loadings for the structural model. $N=971 ; * p<.05$, ** $p<.01$

happiness (Satici 2016). Consequently, resilience and hope are considered as protective factors helping to prevent damage to mental health that may arise from the fear of COVID-19. Therefore, this research tested the role of the fear of COVID-19 as a mediator in the relationship between resilience, hope, and subjective happiness.

The first finding demonstrated that fear of COVID-19 partially mediated the relationship between resilience and subjective happiness supporting $\mathrm{H}_{1}$. For this reason, in preventing individuals from developing a fear of COVID-19, resilience helps to protect their subjective happiness. During the COVID-19 pandemic, individuals have developed symptoms relating to fear, anxiety, depression, and stress (Ahorsu et al. 2020; Qiu et al. 2020; Wang et al. 2020). Eye movement desensitization and reprocessing group therapy carried out for the purpose of increasing resilience has been found to reduce fear (Zaghrout-Hodali et al. 2008). Resilience intervention has also been shown to help individuals developing effective coping strategies (Steinhardt and Dolbier 2008). Therefore, it can be posited that the development of resilience helps in coping with the fear and anxiety caused by COVID-19. Furthermore, previous studies

Table 3 Indirect and total effects on subjective happiness

Coefficient $\quad 95 \% \mathrm{CI}$

Resilience $\rightarrow$ fear of COVID-19 $\rightarrow$ subjective happiness

Total effect (resilience on subjective happiness)

Hope $\rightarrow$ fear of COVID-19 $\rightarrow$ subjective happiness

Total effect (hope on subjective happiness)
LL

.074

.049

$-.056$

.049
$\mathrm{UL}$

$-.024$

.146

Based on 5000 bias-corrected bootstrap sampling

$C I$ confidence interval, $L L$ lower limit, $U L$ upper limit 
have shown that resilience has a positive association with good psychological well-being (Sagone and De Caroli 2014; Souri and Hasanirad 2011) and subjective well-being (Bajaj and Pande 2016), which are widely used to define happiness alongside subjective happiness (Choi and Kim 2018). Consequently, the findings in the present study are consistent with the findings of previous research.

The second finding demonstrated that the relationship between hope and subjective happiness was partially mediated by fear of COVID-19 supporting $\mathrm{H}_{2}$. In other words, those individuals who had a high level of hope experienced low levels of fear of COVID-19, which resulted in protecting their subjective happiness. Just as in previous global pandemics (Mak et al. 2010; Wu et al. 2005), the experiences undergone during COVID-19 have caused posttraumatic stress disorder (PTSD) among a minority of individuals (Bo et al. 2020; Huang et al. 2020). However, hope has a negative association with PTSD and general psychological disorders (Glass et al. 2009; Rawdin et al. 2013). Moreover, interventions directed towards developing hope have been effective in decreasing the development of psychological disorders (Rustøen et al. 2011) and PTSD (Yousefi et al. 2016). On the other hand, hope has a positive correlation with subjective happiness (Sariçam 2015) and subjective well-being (Kato and Snyder 2005; Satici 2016; Shenaar-Golan 2017; Yalçın and Malkoç 2015). Thus, the finding here that hope appears to develop mental health by decreasing fear can be said to exhibit similar features with the findings of previous research.

Finally, resilience and hope, with a low level fear of COVID-19 as a mediator, were shown to predict a high level of subjective happiness. Therefore, with resilience and hope preventing fear of COVID-19 from reaching a level that disrupts daily functioning, the notion that they are helpful in protecting mental health appears feasible. The positive psychology approach posits that resilience and hope are psychological strengths and that instead of treating psychological disorders, developing psychological strengths is an alternative route in protecting mental health (Peterson 2006; Peterson and Seligman 2004). In fact, it has been demonstrated that intervention programs focused on positive psychology decrease fear and increase happiness (Lambert et al. 2019). Moreover, resilience (Choi and Kim 2018; Yildirim and Belen 2019) and hope (Aghababaei et al. 2016; Satici 2016) predict positive subjective happiness. Consequently, the findings here are in alignment with the theoretical knowledge concerning the aforementioned positive psychology, in addition to experimental and cross-sectional research findings (e.g., Lambert et al. 2019; Satici 2016).

\section{Implications}

The findings of the present study fundamentally point to the development of strong psychological attributes being able to assist in the protection of mental health from the fear of COVID-19. Attributes such as resilience and hope can be increased with psychological intervention programs (Davidson et al. 2012; Ritchie et al. 2014; Rosenberg et al. 2015). It is within this context that the development and provision of resilience and hope building intervention programs are recommended as preventive health services, before the fear of COVID-19 sets in and disrupts and/or damages individuals' psychological functioning. When developing resilience and hope intervention programs, if spatial distancing measures put in place to prevent the virus from spreading are taken into consideration, then programs suitable for online administration could be developed accordingly. Indeed, online positive psychology interventions have been shown to be effective in decreasing depression and anxiety and increasing good psychological well-being (Gander et al. 2016; Chakhssi et al. 2018). It may 
be beneficial to design intervention programs so that they may be adapted to be used in a face to face setting, once the risk of the spread of the virus has ceased. Moreover, resilience and hope program interventions in school settings have also demonstrated positive results regarding the development of physical and mental health (Edwards and McClintock 2013; Stallard and Buck 2013). The widespread use of such programs in all schools can be construed as a form of investment in strengthening individuals during the current COVID-19 climate and protection of mental health in the case of any future outbreaks that may occur. Mental health specialists such as psychologists, counselors, social workers, and psychiatric nurses may benefit from the findings of the research here with regard to the struggle in preventing the fear of COVID-19 and the protection of the mental health more generally in society.

\section{Limitations}

There are some limitations present in the present study. Firstly, the data for the study were derived from self-report scales which suffer from well-known method biases. In collecting the data, the use of multiple methods would be beneficial in reducing bias in the answering of questions. Secondly, as the study design was cross-sectional, it is not possible to make definitive conclusions regarding the cause and effect correlations between the variables under investigation. Longitudinal studies are needed to determine the direction of the relationships. Thirdly, while the data were collected from participants across Turkey, the sample was not necessarily nationally representative, so the findings here would need replicating using larger more nationally representative studies both in and outside of Turkey. Finally, only two factors (i.e., hope and resilience) were examined as protective factors against the fear of COVID-19 and only subjective happiness, which is an indicator of mental health, was investigated in the study. For this reason, future research should examine other psychological strengths and attributes such as optimism, humor, creativity, spirituality, and vitality as protective factors, which may also have great utility in developing methods of protection against fear of COVID-19 and improving mental health.

\section{Conclusion}

The protection of mental health due to the consequences of COVID-19 is threatening global health and is currently one of the matters of utmost psychological concern. In light of this, the findings of the present study clearly demonstrate that resilience and hope as protective factors are associated with decreased fear of COVID-19 and increased subjective happiness of individuals. In other words, it appears that individuals who have the strength to cope with stressful life situations and have hope that alternative solutions may be found are more able to cope with challenging life events (in this case, COVID-19). Their experience of fear can be dealt with adaptively at a practical and functioning level and consequently they are able to feel a greater sense of subjective happiness.

Acknowledgments Sources of funding are acknowledged.

\section{Compliance with Ethical Standards}

Conflict of Interest The authors declare that they have no conflict of interests.

Ethical Approval All procedures performed in this study involving human participants were in accordance with the ethical standards of University's Research Ethics Board and with the 1975 Helsinki Declaration. 
Informed Consent Informed consent was obtained from all participants.

Open Access This article is licensed under a Creative Commons Attribution 4.0 International License, which permits use, sharing, adaptation, distribution and reproduction in any medium or format, as long as you give appropriate credit to the original author(s) and the source, provide a link to the Creative Commons licence, and indicate if changes were made. The images or other third party material in this article are included in the article's Creative Commons licence, unless indicated otherwise in a credit line to the material. If material is not included in the article's Creative Commons licence and your intended use is not permitted by statutory regulation or exceeds the permitted use, you will need to obtain permission directly from the copyright holder. To view a copy of this licence, visit http://creativecommons.org/licenses/by/4.0/.

\section{References}

Abad, A., da Silva, J. A., de Paiva Teixeira, L. E. P., Antonelli-Ponti, M., Bastos, S., Mármora, C. H. C., Campos, L. A. M., Paiva, S., de Freitas, R. L., \& da Silva, J. A. (2020). Evaluation of fear and peritraumatic distress during COVID-19 pandemic in Brazil. Advances in Infectious Disease, 10(03), 184-194. https://oi. org/10.4236/aid.2020.103019.

Aghababaei, N., Sohrabi, F., Eskandari, H., Borjali, A., Farrokhi, N., \& Chen, Z. J. (2016). Predicting subjective well-being by religious and scientific attitudes with hope, purpose in life, and death anxiety as mediators. Personality and Individual Differences, 90, 93-98. https://doi.org/10.1016/j.paid.2015.10.046.

Ahorsu, D. K., Lin, C. Y., Imani, V., Saffari, M., Griffiths, M. D., \& Pakpour, A. H. (2020). The fear of COVID19 scale: Development and initial validation. International Journal of Mental Health and Addiction. Advance online publication. https://doi.org/10.1007/s11469-020-00270-8.

Akin, A., \& Satici, S. A. (2011). Subjective happiness scale: A study of validity and reliability. Sakarya University Journal of Education Faculty, 21, 65-77.

Alyami, M., Henning, M., Krägeloh, C. U., \& Alyami, H. (2020). Psychometric evaluation of the Arabic version of the Fear of COVID-19 Scale. International Journal of Mental Health and Addiction. Advance online publication. https://doi.org/10.1007/s11469-020-00316-x.

Anderson, J. C., \& Gerbing, D. W. (1988). Structural equation modeling in practice: A review and recommended two-step approach. Psychological Bulletin, 103(3), 411-423. https://doi.org/10.1037/0033-2909.103.3.411.

Anderson, R. M., Heesterbeek, H., Klinkenberg, D., \& Hollingsworth, T. D. (2020). How will country-based mitigation measures influence the course of the COVID-19 epidemic? The Lancet, 395(10228), 931-934. https://doi.org/10.1016/S0140-6736(20)30567-5.

Bagozzi, R. P., \& Yi, Y. (1988). On the evaluation of structural equation models. Journal of the Academy of Marketing Science, 16(1), 74-94. https://doi.org/10.1007/BF02723327.

Bajaj, B., \& Pande, N. (2016). Mediating role of resilience in the impact of mindfulness on life satisfaction and affect as indices of subjective well-being. Personality and Individual Differences, 93, 63-67. https://doi.org/ 10.1016/j.paid.2015.09.005.

Bitan, D. T., Grossman-Giron, A., Bloch, Y., Mayer, Y., Shiffman, N., \& Mendlovic, S. (2020). Fear of COVID19 scale: Psychometric characteristics, reliability and validity in the Israeli population. Psychiatry Research, 289, 113100. https://doi.org/10.1016/j.psychres.2020.113100.

Bo, H. X., Li, W., Yang, Y., Wang, Y., Zhang, Q., Cheung, T., Wu, X., \& Xiang, Y. T. (2020). Posttraumatic stress symptoms and attitude toward crisis mental health services among clinically stable patients with COVID-19 in China. Psychological Medicine. Advance online publication. https://doi.org/10.1017/ S0033291720000999.

Carver, C. S. (1998). Resilience and thriving: issues, models, and linkages. Journal of Social Issues, 54(2), 245266. https://doi.org/10.1111/j.1540-4560.1998.tb01217.x.

Chakhssi, F., Kraiss, J. T., Sommers-Spijkerman, M., \& Bohlmeijer, E. T. (2018). The effect of positive psychology interventions on well-being and distress in clinical samples with psychiatric or somatic disorders: A systematic review and meta-analysis. BMC Psychiatry, 18(1), 211. https://doi.org/10.1186/s12888018-1739-2.

Choi, W. S., \& Kim, H. Y. (2018). The effects of smartphone addiction on subjective happiness in university students: Mediating effect of resilience. Journal of the Korea Academia-Industrial Cooperation Society, 19(1), 199-207. https://doi.org/10.5762/KAIS.2018.19.1.199.

Chou, K. L. (2000). Assessing Chinese adolescents' social support: The multidimensional scale of perceived social support. Personality and Individual Differences, 28(2), 299-307. https://doi.org/10.1016/S01918869(99)00098-7. 
Conversano, C., Marchi, L., \& Miniati, M. (2020). Psychological distress among healthcare professionals involved in the COVID-19 emergency: Vulnerability and resilience factors. Clinical Neuropsychiatry, 17(2), 94-96.

Davidson, O. B., Feldman, D. B., \& Margalit, M. (2012). A focused intervention for 1st-year college students: Promoting hope, sense of coherence, and self efficacy. Journal of Psychology, 146, 333-352. https://doi.org/ 10.1080/00223980.2011.634862.

Diener, E., Scollon, C. N., \& Lucas, R. E. (2009). The evolving concept of subjective well-being: The multifaceted nature of happiness. In E. Diener (Ed.), Assessing well-being (pp. 67-100). New York: Springer. https://doi.org/10.1007/978-90-481-2354-4 4.

Djalante, R., Shaw, R., \& DeWit, A. (2020). Building resilience against biological hazards and pandemics: COVID-19 and its implications for the Sendai Framework. Progress in Disaster Science, 6, 100080. https:// doi.org/10.1016/j.PDISAS.2020.100080.

Doğan, T. (2015). Adaptation of the brief resilience scale into Turkish: A validity and reliability study. Journal of Happiness \& Well-Being, 3(1), 93-102.

Edwards, L. M., \& McClintock, J. B. (2013). Promoting hope among youth: theory, research, and practice. In C. Proctor \& P. A. Linley (Eds.), Research, applications, and interventions for children and adolescents (pp. 43-55). New York: Springer. https://doi.org/10.1007/978-94-007-6398-2_4.

Fornell, C., \& Larcker, D. F. (1981). Evaluating structural equation models with unobservable variables and measurement error. Journal of Marketing Research, 18(1), 39-50. https://doi.org/10.1177/ 002224378101800104.

Gander, F., Proyer, R. T., \& Ruch, W. (2016). Positive psychology interventions addressing pleasure, engagement, meaning, positive relationships, and accomplishment increase well-being and ameliorate depressive symptoms: A randomized, placebo-controlled online study. Frontiers in Psychology, 7, 686. https://doi.org/ 10.3389/fpsyg.2016.00686.

Glass, K., Flory, K., Hankin, B. L., Kloos, B., \& Turecki, G. (2009). Are coping strategies, social support, and hope associated with psychological distress among Hurricane Katrina survivors? Journal of Social and Clinical Psychology, 28(6), 779-795. https://doi.org/10.1521/jscp.2009.28.6.779.

Griggs, S. (2017). Hope and mental health in young adult college students: An integrative review. Journal of Psychosocial Nursing and Mental Health Services, 55(2), 28-35. https://doi.org/10.3928/0279369520170210-04.

Harper, C. A., Satchell, L. P., Fido, D., \& Latzman, R. D. (2020). Functional fear predicts public health compliance in the COVID-19 pandemic. International Journal of Mental Health and Addiction. Advance online publication. https://doi.org/10.1007/s11469-020-00281-5.

Holmes, E. A., O'Connor, R. C., Perry, V. H., Tracey, I., Wessely, S., Arseneault, L., et al. (2020). Multidisciplinary research priorities for the COVID-19 pandemic: A call for action for mental health science. The Lancet Psychiatry. Advance online publication, 7, 547-560. https://doi.org/10.1016/S2215-0366(20) 30168-1.

Hu, L. T., \& Bentler, P. M. (1999). Cutoff criteria for fit indexes in covariance structure analysis: Conventional criteria versus new alternatives. Structural Equation Modeling, 6(1), 1-55. https://doi.org/10.1080/ 10705519909540118.

Huang, J. Z., Han, M. F., Luo, T. D., Ren, A. K., \& Zhou, X. P. (2020). Mental health survey of 230 medical staff in a tertiary infectious disease hospital for COVID-19. Chinese Journal of Industrial Hygiene and Occupational Diseases, 38, E001. https://doi.org/10.3760/cma.j.cn121094-20200219-00063.

Jackson, D., Firtko, A., \& Edenborough, M. (2007). Personal resilience as a strategy for surviving and thriving in the face of workplace adversity: A literature review. Journal of Advanced Nursing, 60, 1-9. https://doi.org/ 10.1111/j.1365-2648.2007.04412.x.

Kassam, S. (2019). Understanding experiences of social support as coping resources among immigrant and refugee women with postpartum depression: An integrative literature review. Issues in Mental Health Nursing, 40(12), 999-1011. https://doi.org/10.1080/01612840.2019.1585493.

Kato, T., \& Snyder, C. R. (2005). The relationship between hope and subjective well-being: reliability and validity of the dispositional hope scale, Japanese version. Japanese Journal of Psychology, 76(3), $227-234$. https://doi.org/10.4992/jjpsy.76.227.

Lambert, L., Passmore, H. A., \& Joshanloo, M. (2019). A positive psychology intervention program in a culturally-diverse university: Boosting happiness and reducing fear. Journal of Happiness Studies, 20(4), 1141-1162. https://doi.org/10.1007/s10902-018-9993-z.

Lau, A. L., Chi, I., Cummins, R. A., Lee, T. M., Chou, K. L., \& Chung, L. W. (2008). The SARS (severe acute respiratory syndrome) pandemic in Hong Kong: effects on the subjective wellbeing of elderly and younger people. Aging and Mental Health, 12(6), 746-760. https://doi.org/10.1080/13607860802380607.

Little, T. D., Cunningham, W. A., Shahar, G., \& Widaman, K. F. (2002). To parcel or not to parcel: Exploring the question, weighing the merits. Structural Equation Modeling, 9(2), 151-173. https://doi.org/10.1207/ S15328007SEM0902_1. 
Lyubomirsky, S., \& Lepper, H. S. (1999). A measure of subjective happiness: Preliminary reliability and construct validation. Social Indicators Research, 46(2), 137-155. https://doi.org/10.1023/A: 1006824100041.

MacCallum, R. C., Browne, M. W., \& Sugawara, H. M. (1996). Power analysis and determination of sample size for covariance structure modeling. Psychological Methods, 1(2), 130-149. https://doi.org/10.1037/1082989X.1.2.130

Mak, I. W. C., Chu, C. M., Pan, P. C., Yiu, M. G. C., Ho, S. C., \& Chan, V. L. (2010). Risk factors for chronic post-traumatic stress disorder (PTSD) in SARS survivors. General Hospital Psychiatry, 32(6), 590-598. https://doi.org/10.1016/j.genhosppsych.2010.07.007.

Masuyama, A., Shinkawa, H., \& Kubo, T. (2020). Validation and psychometric properties of the Japanese version of the Fear of COVID-19 Scale among adolescents. International Journal of Mental Health and Addiction. Advance online publication. https://doi.org/10.1007/s11469-020-00368-z.

Mertens, G., Gerritsen, L., Salemink, E., \& Engelhard, I. (2020). Fear of the coronavirus (COVID-19): Predictors in an online study conducted in March 2020. PsyArXiv. https://doi.org/10.31234/osf.io/2p57j.

Montemurro, N. (2020). The emotional impact of COVID-19: From medical staff to common people. Brain, Behavior, and Immunity. Advance online publication. https://doi.org/10.1016/j.bbi.2020.03.032.

Mucci, F., Mucci, N., \& Diolaiuti, F. (2020). Lockdown and isolation: psychological aspects of COVID-19 pandemic in the general population. Clinical Neuropsychiatry, 17(2), 63-64.

Nabi, R. L., \& Myrick, J. G. (2019). Uplifting fear appeals: Considering the role of hope in fear-based persuasive messages. Health Communication, 34(4), 463-474. https://doi.org/10.1080/10410236.2017.1422847.

Ornell, F., Schuch, J. B., Sordi, A. O., \& Kessler, F. H. P. (2020). "Pandemic fear" and COVID-19: mental health burden and strategies. Brazilian Journal of Psychiatry, 42, 232-235. https://doi.org/10.1590/1516-44462020-0008.

Pakpour, A. H., \& Griffiths, M. D. (2020). The fear of COVID-19 and its role in preventive behaviors. Journal of Concurrent Disorders, 2(1), 58-63.

Pang, N. T. P., Kamu, A., Hambali, N. L. B., Mun, H. C., Kassim, M. A., Mohamed, N. H., Ayu, F., Rahim, S. S. S. A., Omar, A., \& Jeffree, M. S. (2020). Malay version of the fear of COVID-19 scale: validity and reliability. International Journal of Mental Health and Addiction. Advance online publication. https://doi.org/ 10.1007/s11469-020-00373-2.

Peterson, C. (2006). The values in action (VIA) classification of strengths. In M. Csikszentmihalyi \& I. S. Csikszentmihalyi (Eds.), A life worth living: contributions to positive psychology (pp. 29-48). Oxford: Oxford University Press.

Peterson, C., \& Seligman, M. E. (2004). Character strengths and virtues: A handbook and classification. Oxford: Oxford University Press.

Qiu, J., Shen, B., Zhao, M., Wang, Z., Xie, B., \& Xu, Y. (2020). A nationwide survey of psychological distress among Chinese people in the COVID-19 epidemic: implications and policy recommendations. General Psychiatry, 33(2), e100213. https://doi.org/10.1136/gpsych-2020-100213.

Rawdin, B., Evans, C., \& Rabow, M. W. (2013). The relationships among hope, pain, psychological distress, and spiritual well-being in oncology outpatients. Journal of Palliative Medicine, 16(2), 167-172. https://doi.org/ 10.1089/jpm.2012.0223.

Republic of Turkey Ministry of Health. (2020). Day table of coronavirus in Turkey. Retrieved October 30, 2020, from covid19.saglik.gov.tr/.

Reyes, A. T., Constantino, R. E., Cross, C. L., Tan, R. A., Bombard, J. N., \& Acupan, A. R. (2019). Resilience and psychological trauma among Filipino American women. Archives of Psychiatric Nursing, 33(6), 177185. https://doi.org/10.1016/j.apnu.2019.08.008.

Reznik, A., Gritsenko, V., Konstantinov, V., Khamenka, N., \& Isralowitz, R. (2020). COVID-19 fear in Eastern Europe: Validation of the Fear of COVID-19 Scale. International Journal of Mental Health and Addiction. Advance online publication. https://doi.org/10.1007/s11469-020-00283-3.

Ritchie, S., Wabano, M. J., Russell, K., Enosse, L., \& Young, N. (2014). Promoting resilience and wellbeing through an outdoor intervention designed for Aboriginal adolescents. Rural and Remote Health, 14, 2523.

Rosenberg, A. R., Yi-Frazier, J. P., Eaton, L., Wharton, C., Cochrane, K., Pihoker, C., Baker, K. S., \& McCauley, E. (2015). Promoting resilience in stress management: A pilot study of a novel resiliencepromoting intervention for adolescents and young adults with serious illness. Journal of Pediatric Psychology, 40(9), 992-999. https://doi.org/10.1093/jpepsy/jsv004.

Rustøen, T., Cooper, B. A., \& Miaskowski, C. (2011). A longitudinal study of the effects of a hope intervention on levels of hope and psychological distress in a community-based sample of oncology patients. European Journal of Oncology Nursing, 15(4), 351-357. https://doi.org/10.1016/j.ejon.2010.09.001.

Sadati, A. K. B, Lankarani, M. H., \& Bagheri Lankarani, K. (2020). Risk society, global vulnerability and fragile resilience; sociological view on the coronavirus outbreak. Advances in Shiraz E-Medical Journal. Advance online publication. https://doi.org/10.5812/semj.102263. 
Sagone, E., \& De Caroli, M. E. (2014). A correlational study on dispositional resilience, psychological wellbeing, and coping strategies in university students. American Journal of Educational Research, 2(7), 463471. https://doi.org/10.12691/education-2-7-5.

Sakib, N., Bhuiyan, A. I., Hossain, S., Al Mamun, F., Hosen, I., Abdullah, A. H., ... \& Sikder, M. T. (2020). Psychometric validation of the Bangla Fear of COVID-19 Scale: Confirmatory factor analysis and Rasch analysis. International Journal of Mental Health and Addiction. Advance online publication. https://doi.org/ 10.1007/s11469-020-00289-x.

Sariçam, H. (2015). Subjective happiness and hope. Universitas Psychologica, 14(2), 685-694. https://doi.org/ 10.11144/Javeriana.upsy14-1.shah.

Satici, S. A. (2016). Psychological vulnerability, resilience, and subjective well-being: The mediating role of hope. Personality and Individual Differences, 102, 68-73. https://doi.org/10.1016/j.paid.2016.06.057.

Satici, B., Gocet-Tekin, E., Deniz, M. E., \& Satici, S. A. (2020). Adaptation of the Fear of COVID-19 Scale: Its association with psychological distress and life satisfaction in Turkey. International Journal of Mental Health and Addiction. Advance online publication. https://doi.org/10.1007/s11469-020-00294-0.

Shenaar-Golan, V. (2017). Hope and subjective well-being among parents of children with special needs. Child \& Family Social Work, 22(1), 306-316. https://doi.org/10.1111/cfs.12241.

Shin, Y. C., Kim, S. M., Kim, H., Min, K. J., Yoo, S. K., Kim, E. J., \& Jeon, S. W. (2019). Resilience as a protective factor for depressive mood and anxiety among Korean employees. Journal of Korean Medical Science, 34(27), e188. https://doi.org/10.3346/jkms.2019.34.e188.

Smith, B. W., Dalen, J., Wiggins, K., Tooley, E., Christopher, P., \& Bernard, J. (2008). The brief resilience scale: Assessing the ability to bounce back. International Journal of Behavioral Medicine, 15(3), 194-200. https:// doi.org/10.1080/10705500802222972.

Snyder, C. R. (Ed.). (2000). Handbook of hope: Theory, measures, and applications. New York: Academic Press.

Snyder, C. R., Harris, C., Anderson, J. R., Holleran, S. A., Irving, L. M., Sigmon, S. T., Yoshinobu, L., Gibb, J., Langelle, C., \& Harney, P. (1991). The will and the ways: Development and validation of an individualdifferences measure of hope. Journal of Personality and Social Psychology, 60(4), 570-585. https://doi.org/ 10.1037/0022-3514.60.4.570.

Snyder, C. R., Rand, K. L., \& Sigmon, D. R. (2002). Hope theory: A member of the positive psychology family. In C. R. Snyder \& S. J. Lopez (Eds.), Handbook of positive psychology (pp. 257-276). Oxford: Oxford University Press.

Soraci, P., Ferrari, A., Abbiati, F. A., Del Fante, E., De Pace, R., Urso, A., \& Griffiths, M. D. (2020). Validation and psychometric evaluation of the Italian version of the Fear of COVID-19 Scale. International Journal of Mental Health and Addiction Advance online publication. https://doi.org/10.1007/s11469-020-00277-1.

Souri, H., \& Hasanirad, T. (2011). Relationship between resilience, optimism and psychological well-being in students of medicine. Procedia-Social and Behavioral Sciences, 30, 1541-1544. https://doi.org/10.1016/j. sbspro.2011.10.299.

Stallard, P., \& Buck, R. (2013). Preventing depression and promoting resilience: Feasibility study of a schoolbased cognitive-behavioural intervention. The British Journal of Psychiatry, 202(s54), s18-s23. https:/doi. org/10.1192/bjp.bp.112.119172.

Steinhardt, M., \& Dolbier, C. (2008). Evaluation of a resilience intervention to enhance coping strategies and protective factors and decrease symptomatology. Journal of American College Health, 56(4), 445-453. https://doi.org/10.3200/JACH.56.44.445-454.

Tarhan, S., \& Bacanl1, H. (2015). Adaptation of dispositional hope scale into Turkish: validity and reliability study. Journal of Happiness \& Well-Being, 3(1), 1-14.

Trezise, A., McLaren, S., Gomez, R., Bice, B., \& Hodgetts, J. (2018). Resiliency among older adults: Dispositional hope as a protective factor in the insomnia-depressive symptoms relation. Aging \& Mental Health, 22(8), 1094-1102. https://doi.org/10.1080/13607863.2017.1334191.

Wang, C., Pan, R., Wan, X., Tan, Y., Xu, L., Ho, C. S., \& Ho, R. C. (2020). Immediate psychological responses and associated factors during the initial stage of the 2019 coronavirus disease (COVID-19) epidemic among the general population in China. International Journal of Environmental Research and Public Health, 17(5), 1729. https://doi.org/10.3390/ijerph17051729.

Wilder-Smith, A., Chiew, C. J., \& Lee, V. J. (2020). Can we contain the COVID-19 outbreak with the same measures as for SARS? The Lancet Infectious Diseases, 20(5), e102-e107. https://doi.org/10.1016/S14733099(20)30129-8.

Winter, T., Riordan, B., Pakpour, A., Griffiths, M. D., Mason, A., Poulgrain, J., \& Damian, S. (2020). Evaluation of the English version of the Fear of COVID-19 Scale and its relationship with behavior change and political beliefs. International Journal of Mental Health and Addiction. Advance online publication. https://doi.org/ 10.1007/s11469-020-00342-9. 
Witte, K., \& Allen, M. (2000). A meta-analysis of fear appeals: Implications for effective public health campaigns. Health Education \& Behavior, 27(5), 591-615. https://doi.org/10.1177/109019810002700506.

World Health Organization. (2020). Weekly epidemiological update - 27 October 2020. Retrieved October 30, 2020, from www.who.int/publications/m/item/weekly-epidemiological-update\%2D\%2D-27-october-2020.

Wu, K. K., Chan, S. K., \& Ma, T. M. (2005). Posttraumatic stress after SARS. Emerging Infectious Diseases, 11(8), 1297-1300. https://doi.org/10.3201/eid1108.041083.

Yalçın, I., \& Malkoç, A. (2015). The relationship between meaning in life and subjective well-being: forgiveness and hope as mediators. Journal of Happiness Studies, 16(4), 915-929. https://doi.org/10.1007/s10902-0149540-5.

Yildirim, M., \& Belen, H. (2019). The role of resilience in the relationships between externality of happiness and subjective well-being and flourishing: a structural equation model approach. Journal of Positive Psychology and Wellbeing, 3(1), 62-76.

Yousefi, A., Rafinia, P., \& Sabahi, P. (2016). The effectiveness of hope therapy on quality of life in wives of veterans with post traumatic stress disorder. Journal of Clinical Psychology, 8(1), 1-9.

Zaghrout-Hodali, M., Alissa, F., \& Dodgson, P. W. (2008). Building resilience and dismantling fear: EMDR group protocol with children in an area of ongoing trauma. Journal of EMDR: Practice and Research, 2(2), 106-113. https://doi.org/10.1891/1933-3196.2.2.106.

Zhang, J., Lu, H., Zeng, H., Zhang, S., Du, Q., Jiang, T., \& Du, B. (2020). The differential psychological distress of populations affected by the COVID-19 pandemic. Brain, Behavior, and Immunity. Advance online publication. https://doi.org/10.1016/j.bbi.2020.04.031.

Publisher's Note Springer Nature remains neutral with regard to jurisdictional claims in published maps and institutional affiliations.

\section{Affiliations}

\section{Seydi Ahmet Satici ${ }^{1} \cdot$ Ahmet Rifat Kayis $^{2} \cdot$ Begum Satici $^{1} \cdot$ Mark D. Griffiths $^{3} \cdot$ Gurhan $\mathrm{Can}^{4}$}

Seydi Ahmet Satici

sasatici@artvin.edu.tr

Ahmet Rifat Kayis

arkayis@kastamonu.edu.tr

Begum Satici

begum@artvin.edu.tr

Gurhan Can

gurhan.can@hku.edu.tr

1 Department of Psychological Counselling, Artvin Coruh University, Artvin, Turkey

2 Department of Psychological Counselling, Kastamonu University, Kastamonu, Turkey

3 International Gaming Research Unit, Psychology Department, Nottingham Trent University, 50

Shakespeare Street, Nottingham NG1 4FQ, UK

4 Department of Psychological Counselling, Hasan Kalyoncu University, Gaziantep, Turkey 